\title{
EDTECH EFFECTIVENESS: USING SCREENCASTS TO INCREASE LEARNING OUTCOMES IN INFORMATION SYSTEMS CURRICULA
}

\author{
Adam P. Sullivan, Robert Morris University, sullivana@rmu.edu \\ Gary Alan Davis, Robert Morris University, davis@rmu.edu \\ John C. Stewart, Robert Morris University, stewartj@rmu.edu
}

\begin{abstract}
Education Technology (EdTech) has become increasingly prevalent in higher-education, in both on-ground and online curricula. However, few studies have thoroughly and objectively studied the effectiveness of specific EdTech components, such as Screencast Technology, on learning outcomes. The current study used objective pre-test and post-test results to assess the learning effectiveness of Screencast Technology on students. Specifically, undergraduate, and graduate Information Systems students enrolled in a Data Mining course were tested before, and after watching online Screencast video tutorials. The findings of the study will be of interest to higher-education faculty who are using, or who may consider using, Screencast Technology in their undergraduate or graduate Information Systems curriculum.
\end{abstract}

Keywords: EdTech, Screencast Technology, Online Learning, Video-Based Learning (VBL), Higher Education, Learning Outcomes, Information Systems Curriculum

\section{INTRODUCTION}

Since its formal introduction in the 1970s, Educational Technology (EdTech) has promised increased learning effectiveness for primary, secondary, and higher education (Ely, 1972). For nearly 50 years, academic institutions at all levels have sought to enhance their learning outcomes by acquiring and implementing the latest in classroom technology. More recently, the continued proliferation of online and distance learning has prompted schools to spend millions of dollars on Learning Management Systems (LMS) and other software-based tools for effective and efficient content delivery. Despite the large investments by academia, some authors have questioned the effectiveness of such technology, calling it " . . . anecdotal, unscientific, and sometimes inflated . . . [lacking] long term data that would support claims of retention and achievement gains" ("Effectiveness," 2005, p. 4). However, most academics would agree that technology-enabled learning has become a mandatory curricular component in our mobile, and cloudconnected world (Davis \& Kohun, 2018).

Since the early 2000s, screencast and other video-capture technologies have become an integral part of EdTech and Instructional Technology offerings. As with EdTech, and Instructional Technology in general, the efficacy of specific screencast tools at improving learning outcomes warrants further study.

The purpose of the current study was to analyze any observable effect that screencast or video-based learning has on student learning in undergraduate and graduate data mining courses. The results of the study could increase faculty interest in utilizing screencast and video-based learning tools in Information Systems curricula. Specifically, the study sought to answer the following research questions:

RQ1. Do videos created using Screencast Technology increase student learning at a level that is statistically significant?

RQ2. Do videos created using Screencast Technology increase student learning at a level that is statistically significant for theoretical concept learning?

RQ3. Do videos created using Screencast Technology increase student learning at a level that is statistically significant for practical skills learning? 
RQ4. Are videos created using Screencast Technology more effective for theoretical concept learning or for practical skills learning?

\section{DEFINITION OF TERMS}

Ely (1972) defines Educational Technology (EdTech) as "a field involved in the facilitation of human learning through the systematic identification, development, organizational, and utilization of a full range of learning resources and through the management of these processes" (p. 36). A somewhat newer term that is often used in the same context as EdTech is Instructional Technology. The Association for Education Communication and Technology defines Instructional Technology as, "The theory and practice of design, development, utilization, management, and evaluation of processes and resources for learning" (Seels \& Richey, 1994, p. 1). It should be noted that neither definition above makes mention of computers, laptops, or any other physical device or technological platform. According to Moore (2006), the omission of specific technological devices in these definitions “ . . highlights the notion that technology isn't manifested in physical products ... and that anything that is used to accomplish work can be considered a tool, technology, or instrument" (p. 401-402).

Finally, Ghilay \& Ghilay (2015) define a screencast as “ . . . a digital video and audio recording of what occurs on a presenter's computer screen, [which] can be used to create sophisticated, information-rich multimedia presentations" (p. 15). Screencasts can be step-by-step processes and procedures, course orientations, instructional lectures, a method for offering feedback, and a way to encourage student collaboration (Luongo, 2015). A screencast tool, then, would be any software program that allows for the creation of such rich, multimedia content (i.e., "Screencasts"). Available screencast tools (both commercially available and freeware) include: Camtasia Studio, iShowU HD Pro, Adobe Captivate, ScreenFlow, Jing, Screenr, CamStudio, Community Clips, Free Screencast, ScreenToaster, ScreenCastle and Screencast-o-Matic (Ghilay \& Ghilay, 2015; Luongo, 2015). The current study involved the use of Screencast$o$-Matic, from Big Nerd Software, LLC.

\section{REVIEW OF LITERATURE}

Numerous studies have examined the impact of video technologies on learning effectiveness. Nagy and Bernschütz (2015), for example, analyzed the implementation of a webinar-webcast system. In a study of their college's videoconferencing system, the authors found that the system had a positive impact on student grades (compared to traditional teaching methods), and reduced student dropout rates. According to the authors, "Results have shown that the availability of online videos resulted in significant improvement in semester grades and it [sic] contributed to reducing dropout rates" (p. 1837).

Some researchers specifically compared video-based instruction with traditional face-to-face lecture. In their 2014 study, Park, Kim, Cha, and Nam divided high school students into a face-to-face (i.e., control) group, and a video/elearning (i.e., experiential) group. The authors used one-way analysis of covariance (ANCOVA) to analyze pre-test and post-test results from the students. According to the results, the video/e-learning group demonstrated significantly higher learning outcomes than the face-to-face group.

Other authors have conducted comparative studies of print-based versus video-based instructional materials. Donkor (2010) conducted a study involving 70 students in a distance-learning masonry program. Half of the students in the study reviewed print-based materials, and the other half reviewed video-based materials. Both groups completed a 20-question competency test following the review of materials. The 20-question test was further divided into theoretical knowledge and practical skills-type questions. In the Donkor study, the author found no statisticallysignificant difference in learning outcomes between the two groups in regard to theoretical knowledge. However, the author did note a statistically-significant difference in practical skills learning. Specifically, the students who reviewed the video-based materials performed significantly better on the practical skills-related questions, than students who reviewed print-based materials.

Finally, Brock (2009) studied the impact on learning effectiveness among four types of delivery formats: 1) face-toface, 2) interactive video, 3) minimally interactive online, and 4) highly interactive and multimedia rich online (p. 42). 
In her study, the author collected pre- and post-test scores from 97 students enrolled in a Microsoft Excel 2007 course. Unlike the previous studies discussed, Brock found face-to-face lecture to be the delivery format that was most effective for improving learning outcomes. Although not confirmed, the learning content (i.e., information technology skills/MS-Excel skills) may account for the seemingly contrasting results of the Brock study.

More recent studies have examined screencast technologies, and their impact on learning outcomes. Gambari and Hassan (2017) used a mixed-methods approach to determine student perceptions of, and learning effectiveness of, screencast technologies. Specifically, the authors examined both the test performance, and retention performance of 50 undergraduate Education majors. The authors found that students in the experimental group (i.e., screencast use) had statistically-significantly higher scores than students in the control group (i.e., traditional teaching methods) for both test performance and retention-test performance.

Green, Pinder-Grover, and Millunchick (2012) conducted a quantitative study involving students in an engineering survey course to determine how, and why, students use screencasts. The study also examined student perceptions of screencast technology, in light of student academic performance. The authors of the study noted that the students did experience increased learning outcomes as a result of screencast use. However, the authors found that only those students who had positive perceptions about screencast technology, combined with high frequency of use, experienced positive increases in learning outcomes. Students who did not have a positive perception of screencasts, nor made use of screencasts on a frequent basis, did not experience an increase in learning outcomes.

Finally, Ghilay and Ghilay (2015) conducted a study involving 30 undergraduate students in two computing courses. Specifically, the study sought to determine the advantages of screencast technology for improving learning in a computing curriculum. From an analysis of closed-ended questionnaires, the authors found:

Adding of [screencast] videos to computer courses has a significant contribution to the whole learning process, namely, fully understand and assimilate the material, cover the entire curriculum, accomplish gaps if exist [sic] and continuously follow all routines and principles being taught. (p. 23)

Past studies examining the learning effectiveness of video-based, and screencast technologies have yielded promising results. As past studies have shown, the impact on learning effectiveness can, however, be dependent on the curriculum being taught (Brock, 2009), and/or the individual perceptions of student learners (Green, Pinder-Grover, \& Millunchick, 2012). Further still, many authors argue that video and screencast technology must be designed properly in order to have positive effects on learning outcomes (Chang \& Hannafin, 2015).

In regard to information technology and information systems curricula, the existing body of academic research into the learning effectiveness of video-based and screencast technologies is insufficient. In addition, the number of objective, quantitative studies that specifically isolate and examine screencast technologies is minimal. The current study sought to address both shortcomings in the existing literature. The current study does not, however, discuss design best practices of screencast educational content.

\section{RESEARCH METHODOLOGY}

This study was conducted to determine whether a significant difference in knowledge transfer and ability to apply concepts was enhanced when students had access to a screencast video (i.e., "screencasts"), with both audio and textual script provided to enhance the course material. The specific screencast tool used in the study was Screencast-O-Matic, developed and distributed by Big Nerd Software, LLC. The research participants were undergraduate and graduate students enrolled in an Introduction to Data Mining course.

This study encompassed a pre-test (prior to) and post-test (subsequent to) assessment. In between the pre- and posttest assessments, the student participants viewed online screencast videos showing the students, step-by-step, how to undertake a data mining analysis of a data set using XLMiner. XLMiner is an Excel add-in from Frontline Systems, Inc. Fifty-one students in four different class sections took both pre- and post-tests, for a total of 102 test results. Specific testing was accomplished using a 10-question multiple choice test. Five questions addressed practical skills in utilizing the analytical methodology, and five questions measured the theoretical concept knowledge that the 
student participants gained from the screencasts. A standard, timed, online multiple-choice test format was used for assessment, and to evaluate the effectiveness of this method of knowledge transfer. The results of both practical skills and theoretical concept learning were assessed separately, and then combined to determine an overall measurement of the level of knowledge transfer and learning via the use of screencast videos.

A Paired Samples t-test $(\alpha=0.05)$ was used as the criteria in evaluating the differences in both concept comprehension and applied skills ability, before and after students viewed the posted online screencast videos. The test results were then combined to gain an overall assessment. Consequently, paired samples t-test results were determined on three sets of data: 1) practical skills comprehension, 2) theoretical concept comprehension, and 3) a combination of both practical skills comprehension and theoretical concept comprehension.

\section{RESEARCH PARTICIPANTS}

As stated previously, a total of 51 students participated in this study. The research participants were comprised of undergraduate and graduate students enrolled in four separate sections of an Introduction to Data Mining course. The students in each class section completed two sets of pre- and post-test assessments over a two-week period. Within the group of student participants, slightly over two thirds were male $(68.6 \%)$ and nearly half $(47.1 \%)$ were international students. Finally, 39.2\% of the participants were undergraduate students; the remaining $60.8 \%$ were graduate students. Table 1. Participant Demographics by Sex, and Table 2. Participant Demographics by Country of Origin show the demographic breakdown of the research participants.

Table 1. Participant Demographics by Sex

Demographic Breakdown of Research Participants by Class Section and Sex

\begin{tabular}{|l|c|c|c|}
\hline \multirow{2}{*}{ Class Section } & \multicolumn{2}{|c|}{ Sex } & $\begin{array}{c}\text { Total Students } \\
\text { by Section }\end{array}$ \\
\hline Undergraduate Section A & $6(54.5 \%)$ & $5(45.5 \%)$ & $11(21.6 \%)$ \\
\hline Undergraduate Section B & $7(77.8 \%)$ & $2(22.2 \%)$ & $9(39.2 \%)$ \\
\hline Graduate Section A & $9(60.0 \%)$ & $6(40.0 \%)$ & $15(68.6 \%)$ \\
\hline Graduate Section B & $13(81.3 \%)$ & $3(18.7 \%)$ & $16(100.0 \%)$ \\
\hline Total & $\mathbf{3 5 ( 6 8 . 6 \% )}$ & $\mathbf{1 6}(\mathbf{3 1 . 4 \%})$ & $\mathbf{5 1 ( 1 0 0 . 0 \% )}$ \\
\hline
\end{tabular}

Table 2. Participant Demographics by Country of Origin

Demographic Breakdown of Research Participants by Class Section and Country of Origin

\begin{tabular}{|l|c|c|c|}
\hline \multirow{2}{*}{ Class Section } & \multicolumn{2}{|c|}{$\begin{array}{c}\text { Country of Origin } \\
\text { Domestic }\end{array}$} & $\begin{array}{c}\text { Total Students } \\
\text { by Section }\end{array}$ \\
\hline Undergraduate Section A & $10(90.1 \%)$ & $1(0.9 \%)$ & $11(21.6 \%)$ \\
\hline Undergraduate Section B & $5(55.6 \%)$ & $4(44.4 \%)$ & $9(39.2 \%)$ \\
\hline Graduate Section A & $7(46.7 \%)$ & $8(53.3 \%)$ & $15(68.6 \%)$ \\
\hline Graduate Section B & $5(31.3 \%)$ & $11(68.7 \%)$ & $16(100.0 \%)$ \\
\hline Total & $\mathbf{2 7}(\mathbf{5 2 . 9 \% )}$ & $\mathbf{2 4}(\mathbf{4 7 . 1 \% )}$ & $\mathbf{5 1 ( 1 0 0 . 0 \% )}$ \\
\hline
\end{tabular}

RESULTS 
In order to address the first research question, "Do videos created using Screencast Technology increase student learning at a level that is statistically significant?," the participants answered pre- and post-test questions that assessed both theoretical concept learning and practical skills learning. The assessment data resulting from both the theoretical concept questions and practical skills questions were combined and a Paired Samples t-test $(\alpha=0.05)$ was performed on the entire data set. Table 3: T-Test Results - Overall Learning shows the t-test results of the combined data.

As displayed in Table 3, there was an increase in participant learning between pre- $(\mathrm{M}=62.35, \mathrm{SD}=21.30)$ and posttest $(\mathrm{M}=86.76, \mathrm{SD}=16.95)$ results. In addition, as indicated by a t-statistic of -12.83 , the increase in learning between pre- and post-test results occurred at a level that was statistically significant, $\mathrm{t}(101)=-12.83, \mathrm{p}=.000$.

Table 3. T-Test Results - Overall Learning

Paired Samples T-Test Results of Pre-and Post-Testing of Combined Practical Skills and Theoretical Concept Comprehension by Participants

\begin{tabular}{|l|r|r|r|r|r|r|}
\hline $\begin{array}{l}\text { Overall Learning } \\
\text { (both Practical } \\
\text { and Theoretical combined) }\end{array}$ & Mean & N & Std. Deviation & t & df & Sig. \\
\hline Pre-Test & 62.35 & 102 & 21.303 & -12.827 & 101 & .000 \\
\cline { 1 - 5 } Post-Test & 86.76 & 102 & 16.954 & & \\
\hline
\end{tabular}

The second research question proposed was, "Do videos created using Screencast Technology increase student learning at a level that is statistically significant for theoretical concept learning?" In order to address this research question, only the pre- and post-test results from the theoretical concept questions were analyzed.

Table 4. T-Test Results - Theoretical Concept Learning shows the comparison of average scores for both the pre- and post-testing from the theoretical concepts comprehension portion of the assessment. Again, the mean scores between pre-test $(M=65.10, S D=29.48)$ and post-test $(M=86.67, S D=20.36)$ show an increase in participant learning. In addition, the t-statistic shows a statistically significant difference in pre- and post-test results, $\mathrm{t}(101)=-7.26, \mathrm{p}=.000$.

Table 4. T-Test Results - Theoretical Concept Learning

Paired Samples T-Test Results of Pre-and Post-Testing of Theoretical Concept Comprehension by Participants

\begin{tabular}{|l|c|c|c|c|c|c|}
\hline $\begin{array}{l}\text { Theoretical } \\
\text { Concept } \\
\text { Learning }\end{array}$ & Mean & N & Std. Deviation & t & df & Sig. \\
\hline Pre-Test & 65.10 & 102 & 29.475 & -7.259 & 101 & .000 \\
\hline Post-Test & 86.67 & 102 & 20.360 & & \\
\hline
\end{tabular}

The third research question proposed was, "Do videos created using Screencast Technology increase student learning at a level that is statistically significant for practical skills learning?" In order to address this research question, only the pre- and post-test results from the practical skills questions were analyzed.

Table 5. T-Test Results - Practical Skills Learning shows the comparison of average scores for both the pre-testing $(M=59.61, S D=4.48)$ and post-testing $(M=86.86, S D=4.14)$ from the practical skills component of the assessment. The resulting t-statistic shows a significant difference in pre- and post- assessment of practical skills learning, $t(101)=-$ 
$11.16, \mathrm{p}=.000$. In addition, the difference in learning for the practical skills questions was at a greater level $(\mathrm{t}=-11.16)$, than the difference in learning for theoretical concept questions ( $t=-7.26)$.

Table 5. T-Test Results - Practical Skills Learning Paired Samples T-Test Results of Pre- and Post-Testing of Practical Skills Comprehension by Participants

\begin{tabular}{|l|c|c|c|c|c|c|}
\hline $\begin{array}{l}\text { Practical } \\
\text { Skills } \\
\text { Learning }\end{array}$ & Mean & N & Std. Deviation & t & df & Sig. \\
\hline Pre-Test & 59.61 & 102 & 4.48 & -11.161 & 1,101 & .000 \\
\cline { 1 - 4 } Post-Test & 86.86 & 102 & 4.14 & & \\
\hline
\end{tabular}

The fourth and final research question sought to determine if screencast videos were more effective for theoretical concept learning or for practical skills learning. Specifically, the question asked, "Are videos created using Screencast Technology more effective for theoretical concept learning or for practical skills learning?" In order to answer this question, the t-statistic was compared between the theoretical concept results and the practical skills results. In comparing Tables 4 and 5, both the theoretical concept component and the practical skills component showed an increase in learning that was at a statistically-significant level $(\alpha=0.05)$. However, the difference in theoretical concept learning ( $\mathrm{t}=-7.26)$ does not appear to be as high as was the case with the practical skills component of the assessment $(\mathrm{t}=-11.16)$. This may indicate (at least in the current study) that the use of screencast technology was slightly more effective at conveying the applied, practical components of the course material, as opposed to the conveyance of broader, theoretical concepts.

It should also be noted that the combined effect of both theoretical concept learning and practical skills learning ( $\mathrm{t}=-$ 12.83), yielded a much greater difference in learning than each of the individual learning concepts tested separately $(\mathrm{t}=-7.26$ and $\mathrm{t}=-11.16$, respectively). This increase in overall learning among the study participants suggests that there may be a synergistic effect of combining both learning components (i.e., theoretical concept and practical skills) within a single screencast video lesson.

\section{CONCLUSIONS}

The current study sought to determine if screencast technology was effective at improving learning outcomes among students in an Information Systems course. The study utilized a specific screencast tool, called Screencast-o-Matic, to examine any notable impacts to theoretical concept learning, practical skills learning, and overall student learning. Media-rich video tutorials, created with Screencast-o-Matic software, were used to convey theoretical and practical concepts to undergraduate and graduate students in a data mining course. An analysis of pre- and post-test results revealed a statistically-significant improvement in both theoretical concept learning and practical skills learning, as well as overall learning.

The results of the current study are consistent with a past study by Donkor (2010). In his study, Donkor noted a statistically-significant improvement in practical skills learning when video-based instruction materials were used with students. Unlike the Donkor study, however, the current study also found a statistically-significant increase in theoretical concept learning, in addition to the increase in practical skills learning. The Donkor study also compared video-based content delivery with print-based content delivery. Even though the findings of the two studies are similar, the current study did not include a comparison of screencast video content with print-based learning materials.

While the current study was specific to the effectiveness of screencast technology at improving learning outcomes related to data mining concepts, the technology has broad implications for providing similar knowledge transfer across all Information Systems curricula. In a specific example related to Information Systems curricula, screencast 
technology supports several learning outcomes defined by $A B E T-C A C$ accreditation. Specific ABET-CAC learning outcomes supported by screencast technology include: 1) applying discipline appropriate knowledge, 2) problem analysis, and definition of solution requirements, 3) design and implementation of computer-based processes or programs, and 4) practical use of current techniques and tools (“ABET," 2016).

While the findings of the current study support the effectiveness of screencast technologies within the Information Systems curriculum, further research is needed to compare the capability of screencast content delivery to groundbased, or traditional classroom instruction. Future studies in this area could compare the use of screencast video instruction to traditional classroom instruction, such as in the 2014 Park, Kim, Cha, and Nam study. An extension of this work could compare instructor-led demonstrations to screencast videos. Such a study could determine the delivery method that might be superior, in terms of effective knowledge transfer of Information Systems concepts.

Finally, a more robust study of screencast technology could explore the design best practices required for creating effective learning content. Such a study would build on the work of Chang and Hannafin (2015) and could reveal if, and how, specific screencast video design impacts learning effectiveness. Despite the need for continued research into such tools, it is clear that innovative educators will continue to include screencast technology in their curricula for many years to come.

\section{REFERENCES}

ABET Board of Delegates (2016, October 29). Criteria for accrediting computing programs, 2017 - 2018: General criterion 3. Student outcomes. Retrieved from http://www.abet.org/accreditation/accreditation-criteria/ criteria-for-accrediting-computing-programs-2017-2018/\#objectives

Brock, M. A. (2009). The effectiveness of distance education for computer application software instruction versus the cost of development and implementation (Order No. 3386306). Available from ProQuest Central; ProQuest Dissertations \& Theses Global. (304941911).

Chang, Y. \& Hannafin, M. J. (2015). The uses (and misuses) of collaborative distance education technologies implications for the debate on transience in technology. Quarterly Review of Distance Education, 16(2), 77-92, 148-149.

Davis, G. A., \& Kohun, F. G. (2018). Information and communication technology in the classroom: BYOD and the university's role. Information Systems Education Journal, 16(5), 4-11.

Donkor, F. (2010). The comparative instructional effectiveness of print-based and video-based instructional materials for teaching practical skills at a distance. International Review of Research in Open and Distance Learning, 11(1).

Effectiveness of most EdTech remains unproven. (2005). Curriculum Review, 44(5), 4.

Ely, D. P. (1972). Defining the field of educational technology. Audiovisual Instruction, 18(3), 52-53.

Gambari, A. I., \& Hassan, S. A. (2017). Effects of instructional screencast on the performance of national open university undergraduates in educational technology in Kwara State, Nigeria. Bulgarian Journal of Science and Education Policy, 11(1), 132-159.

Ghilay, Y., \& Ghilay, R. (2015). Computer courses in higher-education: Improving learning by screencast technology. I-Manager's Journal of Educational Technology, 11(4), 15-26.

Green, K. R., Pinder-Grover, T., \& Millunchick, J. M. (2012). Impact of screencast technology: Connecting the perception of usefulness and the reality of performance. Journal of Engineering Education, 101(4), 717 737. 


\section{Issues in Information Systems}

Volume 19, Issue 1, pp. 210-217, 2018

Januszewski, A. (1994). The definition of educational technology: An intellectual and historical account (Order No. 9522531). Available from ProQuest Dissertations \& Theses Global. (304140396).

Luongo, N. (2015). Missing the chalkboard: Using screencasting in the online classroom. Computers in the Schools, $32,144-151$.

Moore, D. R. (2006). The Technology/Inquiry typology: Defining instructional technology. Journal of Interactive Learning Research, 17(4), 401-406.

Nagy, J. T., \& Bernschütz, M. (2016). The impact of webinar-webcast system on learning performance. Education and Information Technologies, 21(6), 1837-1845.

Park, S. Y., Kim, S., Cha, S., \& Nam, M. (2014). Comparing learning outcomes of video-based e-learning with faceto-face lectures of agricultural engineering courses in Korean agricultural high schools. Interactive Learning Environments, 22(4), 418-428.

Seels, B. \& Richey, R. (1994). Instructional technology: the definition and domains of the field. Washington D.C.: Associations for Communications and Technology. 